\title{
Proven Strategies to Reduce Cardiovascular Mortality in Hemodialysis Patients
}

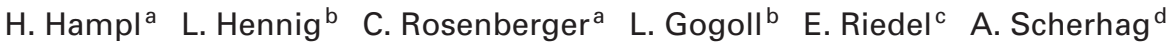 \\ a Nierenzentrum, Kuratorium für Heimdialyse und Nierentransplantation, ${ }^{b}$ Institute of Cardiology, and \\ ${ }^{c}$ Department of Chemistry/Biochemistry, Freie Universität Berlin, Berlin, and ${ }^{\mathrm{d}}$ Department of Cardiology, \\ 1st Medical Clinic, University Hospital Mannheim, University of Heidelberg, Heidelberg, Germany
}

\section{Key Words}

Left ventricular hypertrophy · Optimized cardiac

therapy · Total anemia correction · Hemodialysis
The annual cardiovascular mortality was $5 \%$. Even anemia correction from 12 to $14 \mathrm{~g} / \mathrm{dl}$ results in further $(\mathrm{p}<$ 0.001 ) regression of LVMI.

Copyright (C) 2006 S. Karger AG, Basel

\begin{abstract}
Background: In hemodialysis patients, left ventricular hypertrophy (LVH) correlates with mortality. The reason for LVH in uremics is multifactorial. The primary objective of our study was to investigate the effects of a multiinterventional treatment strategy on LVH. Methods: In 230 ambulatory patients, including patients with coronary artery disease, diabetes, diastolic and systolic dysfunction, we continued optimized cardiac therapy ( $\beta$ blockers, angiotensin-converting enzyme inhibitors and angiotensin receptor blockers) with full anemia correction by intravenous epoetin- $\beta$. The dose of epoetin- $\beta$ for maintaining target hemoglobin $(\mathrm{Hb})$ was $68 \pm 23 \mathrm{lU} / \mathrm{kg} /$ week. Serial echocardiograms were recorded every 3-6 months. The mean observation period was $4.8 \pm 1.2$ years. Results: Mean $\mathrm{Hb}$ at baseline was $11.2 \pm 2.0$ versus $14.1 \pm 1.4 \mathrm{~g} / \mathrm{dl}(\mathrm{p}<0.001)$ at study end. There was a significant reduction in left ventricular mass index (LVMI: $159 \pm 50.4$ vs. $\left.130.2 \pm 42.7 \mathrm{~g} / \mathrm{m}^{2} ; \mathrm{p}<0.001\right)$. In a subgroup of $2 / 3$ of the patients, LVMI returned to normal (169 \pm 33 vs. $\left.114 \pm 14 \mathrm{~g} / \mathrm{m}^{2} ; \mathrm{p}<0.001\right)$. Conclusion: Baseline LVMI ( $p<0.001)$, Hb increase ( $<<0.03$ ), and triple cardiac therapy $(p<0.03$ ) were significant and independent prognostic factors for a reduction in LVMI.
\end{abstract}

\section{Introduction}

In uremic patients [1-5], as in the general population [6-8], mortality correlates with the presence, extent and progression of left ventricular hypertrophy ( $\mathrm{LVH})$, which has emerged as an independent predictor of clinical outcome $[9,10]$. LVH develops in response to numerous factors such as volume overload, metabolic acidosis, arterial hypertension, renal anemia, increased oxidative stress, severe secondary hyperparathyroidism, neurohumoral imbalance including activation of renin-angiotensinaldosterone system (RAAS) and increased sympathetic tone. Arterial hypertension and renal anemia are considered to be most important for the development of concentric/excentric LVH. Therefore, both risk factors are important targets for therapeutic intervention in uremic patients. However, the optimal target hemoglobin $(\mathrm{Hb})$ level to be aimed for by respective treatment regimes with erythropoietin in hemodialysis (HD) patients is still a matter of debate.

Recent studies also show that cardiac medications known for reducing cardiovascular risk are largely underprescribed in end-stage renal disease $[11,12]$. Despite a

\section{KARGER}

Fax +4161306 1234 E-Mail karger@karger.ch www.karger.com
(C) $2006 \mathrm{~S}$. Karger $\mathrm{AG}$, Basel

$0253-5068 / 06 / 0241-0100 \$ 23.50 / 0$

Accessible online at: www.karger.com/bpu
Prof. Dr. Hannelore Hampl

Kuratorium für Dialyse und Nierentransplantation eV

Nierenzentrum, Bismarckstr. 97/98

DE-10 625 Berlin (Germany)

Tel. +49 3031586 422, Fax +49 30313 3803, E-Mail wh189@web.de 
high prevalence of $\mathrm{LVH}$ and chronic heart failure (CHF), a $40 \%$ prevalence of coronary artery disease (CAD) and a 25-50\% prevalence of diabetes mellitus among HD patients, only about $26 \%$ are treated with $\beta$-blockers, $32 \%$ with angiotensin-converting enzyme (ACE) inhibitors and only $1 \%$ with angiotensin II type 1 receptor blockers (ARBs) [13]. Moreover, non-adherence to the current guidelines for the optimal management of acute myocardial infarction [14] or CHF after a first hospital admission for CHF symptoms or cardiac decompensation might partly explain why the reported 3-year mortality is 89 and $83 \%$, respectively [15].

LVH demands increased oxygen delivery by the coronary arteries. The increased cardiac muscle mass interferes with capillary blood flow resulting in reduced coronary reserve, the so called 'cardiomyocyte/capillary mismatch' [16]. Therefore, severe LVH predisposes ventricular arrhythmia triggered by the critically reduced coronary reserve. This often leads to sudden cardiac death. Treatment used is restoration of oxygen delivery and regression of LVH.

Insufficient oxygen delivery to tissues results in a compensatory increase in cardiac output, even at rest. Clinically, this is manifested as chronic tachycardia and increased stroke volume mediated by an increased sympathetic activity. The added work load by the heart results in higher oxygen consumption by the myocardium [17].

A shortened diastole due to tachycardia is uneconomical and damaging to the myocardium, since the myocardium draws on its oxygen during the diastole. Correction of anemia normalizes the cardiac output and tachycardia, which significantly improves the oxygen supply in diastole.

In $\mathrm{LVH}$, an increased sympathetic tone and an activated RAAS contribute to structural and functional transformation of the myocardium (remodeling).

From this pathophysiological point of view, the question arises whether total regression of $\mathrm{LVH}$ is possible by optimized heart failure therapy (combination of $\beta$-blockers, ACE inhibitors and ARBs to target doses) and total anemia correction by erythropoietin?

\section{Study Objectives and Endpoints}

The primary objective of our study was to investigate the effects of the treatment strategy in patients on longterm HD. The primary end point was the LVMI, secondary end points were left ventricular ejection fraction (LVEF), New York Heart Association (NYHA) class, body mass index (BMI), morbidity and mortality. All study end points were compared from baseline to followup. Predefined subgroup analyses included patients with diabetes mellitus, CAD, low LVEF ( $\leq 35 \%)$, and arterial hypertension (blood pressure $\geq 130 / 80 \mathrm{~mm} \mathrm{Hg}$ ) at baseline.

\section{Patients and Methods}

We enrolled 230 consecutive patients from our HD outpatient unit. All patients gave their informed consent to participate. Patients were either initiated or uptitrated to target doses of $190 \mathrm{mg}$ metoprolol, $10 \mathrm{mg}$ ramipril and $32 \mathrm{mg}$ candesartan, or maximally tolerated doses.

Daily drug combination treatment (percent of target doses) at the beginning/end of therapy was as follows: $190 \mathrm{mg}$ metoprolol (target) $38 / 75 \%, 10 \mathrm{mg}$ ramipril (target) $34 / 76.8 \%, 32 \mathrm{mg}$ candesartan (target) 7.8/78.2\%, and $20 \mathrm{mg}$ simvastatin (target) $45.2 / 62.6 \%$. The therapeutic strategies employed were predialytic $\mathrm{HCO}_{3}^{-}$ $\geq 22 \mathrm{mmol} / \mathrm{l}$, predialytic $\mathrm{Hb} 13.5 \mathrm{~g} / \mathrm{dl}$ (females), $14.5 \mathrm{~g} / \mathrm{dl}$ (males), target blood pressure $\leq 130 / 80 \mathrm{~mm} \mathrm{Hg}$, heart rate approximately $60-70$ beats $/ \mathrm{min}$, serumalbumin $\geq 3.5 \mathrm{~g} / \mathrm{dl}, \mathrm{Ca} / \mathrm{PO}_{4}$ product $\leq 4.6 \mathrm{mmol}^{2} / \mathrm{l}^{2}$. Frequently, total parathyroidectomy was performed in the presence of severe hyperparathyroidism.

To correct anemia to normal target $\mathrm{Hb}$ of approximately $14.0 \mathrm{~g} /$ $\mathrm{dl}$, iron was initially used intravenously if deficiency was noted (20-120 mg FelII-Na-gluconate complex weekly). Epoetin- $\beta$ was used intravenously only after iron repletion was accomplished. Iron and epoetin- $\beta$ were never interrupted, but reduced to maintain Hb 13.5-14.5 g/dl. The weekly dose per patient was iron (i.v.) $36 \pm 18 \mathrm{mg} /$ week and epoetin- $\beta$ (i.v.) $68 \mathrm{IU} / \mathrm{kg}$ (approximately $5,100 \mathrm{IU} / \mathrm{kg} /$ week maintaining dose).

In case of deficiencies, after each HD session, we intravenously substituted carnitine, folic acid, vitamins $\mathrm{B}_{1}, \mathrm{~B}_{6}, \mathrm{~B}_{12}$, biotine, nicotinamid and dexpanthenol.

Baseline characteristics of patients are given in table 1.

Serial echocardiographies were performed every 3-6 months (same cardiologist, small dialysis interval). We measured left ventricular end-diastolic diameter, left atrium, septal end-diastolic diameter, posterior wall thickness, LVEF, and fractional shortening. LVMI was calculated as described in Devereux and Reichek [9]. Normal values were $<110 \mathrm{~g} / \mathrm{m}^{2}$ (females) and $<130 \mathrm{~g} / \mathrm{m}^{2}$ (males).

HD was performed for $4 \mathrm{~h} 3$ times/week. The dialysate contained $140 \mathrm{mmol} / \mathrm{l}$ sodium, 1-3 $\mathrm{mmol} / \mathrm{l}$ potassium, 1.5$1.75 \mathrm{mmol} / 1$ calcium, $36-42 \mathrm{mmol} / 1$ bicarbonate, and $1 \mathrm{~g} / 1$ glucose. We did aim for optimal correction of metabolic acidosis. Potassium balance was achieved using individually adjusted bicarbonate substitution.

\section{Statistical Analysis}

Data were expressed as mean \pm SD where appropriate. For statistical comparison of means, Student's t test for unpaired samples or, where applicable, the Mann-Whitney U test was used. ANOVA was used to compare the serial changes over time between groups. Multivariate regression analysis was performed to evaluate the effects of various covariates on LVMI. A $p$ value $<0.05$ was considered to be significant. 
Table 1. Baseline characteristics of HD patients $(n=230)$

\begin{tabular}{|c|c|}
\hline Mean age of HD patients, years & $57.5 \pm 7.8$ \\
\hline Mean age of diabetics $(n=60)$, years & $66.7 \pm 12.1$ \\
\hline \multicolumn{2}{|l|}{ Gender } \\
\hline Female HD patients & 104 \\
\hline Male HD patients & 126 \\
\hline Female diabetics & 29 \\
\hline Male diabetics & 31 \\
\hline Malignancies, $\%$ & 16.8 \\
\hline Arterial hypertension, $\%$ & 73 \\
\hline Use of $\beta$-blockers, $\%^{1}$ & 51.8 \\
\hline Use of ACE inhibitors, $\%^{1}$ & 38.3 \\
\hline Use of ARBs, $\%^{1}$ & 12.9 \\
\hline \multicolumn{2}{|l|}{ Mean duration on dialysis ${ }^{2}$, years } \\
\hline HD patients & $13.1 \pm 8.5$ \\
\hline Diabetics & $8.4 \pm 2.6$ \\
\hline Native arteriovenous fistula, $\%$ & 84 \\
\hline Arteriovenous graft, $\%$ & 16 \\
\hline Previous renal transplant, $\%$ & 12.3 \\
\hline \multicolumn{2}{|l|}{ Underlying renal disease } \\
\hline Diabetes mellitus, $\%^{3}$ & 26 \\
\hline Chronic glomerulonephritis, $\%$ & 13.1 \\
\hline Nephroangliosclerosis, \% & 21 \\
\hline Polycystic kidney disease, $\%$ & 10.3 \\
\hline Interstitial nephritis, $\%$ & 7.3 \\
\hline Urinary reflux and obstruction, $\%$ & 13.1 \\
\hline Others, $\%$ & 9.2 \\
\hline Chronic hepatitis B, \% & 7.5 \\
\hline Chronic hepatitis $\mathrm{C}, \%$ & 11.5 \\
\hline $\mathrm{CAD}, \%$ & 39 \\
\hline Cardiac valvular disease, $\%$ & 16 \\
\hline Low LVEF $\leq 35 \%, \%$ & 14 \\
\hline Cerebrovascular disease, $\%$ & 8.5 \\
\hline Peripheral artery disease, $\%$ & 21.5 \\
\hline \multicolumn{2}{|l|}{ NYHA stages, $\%$} \\
\hline Class I & $<0.1$ \\
\hline Class II & 34 \\
\hline Class III & 47 \\
\hline Class IV & 18 \\
\hline \multicolumn{2}{|c|}{$\begin{array}{l}{ }^{1} \text { Not related to target dose. } \\
{ }^{2} \text { Six months to } 5 \text { years }(n=120), 5-10 \text { years }(n=64), 10-20 \\
\text { years }(n=30), 20-25 \text { years }(n=7), 25-30 \text { years }(n=8), 37 \text { years } \\
(n=1) . \\
\quad{ }^{3} \text { Type } 1(n=5) \text {, type } 2(n=55) .\end{array}$} \\
\hline
\end{tabular}

\section{Results}

All measured echocardiographic parameters concerning the LVMI showed significant reduction. Therefore, the LVMI was significantly reduced and accompanied by an improved contractility of the left ventricle expressed by the significantly increased LVEF in patients (table 2).
Table 2. Echocardiographic parameters in HD patients $(n=230)$

\begin{tabular}{lccc}
\hline & Study start & Study end & p value \\
\hline Hb, g/dl & $11.2 \pm 2.2$ & $14.1 \pm 1.4$ & $<0.001$ \\
LV-ED, mm & $54.5 \pm 7.1$ & $51.7 \pm 6.5$ & $<0.005$ \\
LA, mm & $42.0 \pm 7.6$ & $41.2 \pm 7.2$ & n.s. \\
Sept-ED, mm & $11.5 \pm 2.1$ & $10.4 \pm 1.9$ & $<0.001$ \\
PW-ED, mm & $10.9 \pm 2.1$ & $9.8 \pm 1.6$ & $<0.001$ \\
FS, \% & $33.4 \pm 8.9$ & $35.7 \pm 7.5$ & $<0.05$ \\
LVEF, \% & $59.6 \pm 13.5$ & $66.6 \pm 10.0$ & $<0.001$ \\
LVMI, g/m & $159.0 \pm 50.4$ & $130.2 \pm 42.7$ & $<0.001$ \\
\hline
\end{tabular}

HD patients include 104 females and 126 males. LV-ED = Left ventricular end-diastolic diameter; LA = left atrial diameter; Sept$\mathrm{ED}=$ end-diastolic intraventricular septal thickness; PW-ED = enddiastolic posterior wall; FS = fractional shortening; n.s. = not significant.

\section{Circulation Parameter/Target of Cardiac Triple \\ Therapy}

The significant increased cardiac triple therapy resulted in a significant reduction in blood pressure and heart frequency (table 3).

\section{Diastolic Dysfunction/NYHA Class/BMI}

A reduced LVEF of the heart is indicative of systolic dysfunction. Diastolic dysfunction may be present even in the presence of a normal or increased LVEF, like in the early stage of diabetes mellitus. Patients can suffer from clinical congestive heart failure, even if the LVEF is normal. Therefore, the clinical definition of cardiac insufficiency is essential and best characterized by the NYHA stages.

Table 4 shows the development of NYHA stages over time. In summary, there was a significant improvement in NYHA stages. Especially NYHA classes III and IV were significantly reduced from baseline to follow-up.

Following the improvement in cardiac insufficiency which induces hypercatabolic metabolism like chronic anemia in the patients, the BMI increased significantly in the follow-up of our therapeutic strategy (table 4).

\section{Clinical Outcome}

The annual all-cause mortality was $13.2 \%$, whereas the annual cardiovascular mortality decreased significantly to only $5 \%$. Three patients developed a non-fatal myocardial infarction during intercurrent surgical procedures due to severe bleeding (drop of $2-4 \mathrm{~g} / \mathrm{dl}$ in $\mathrm{Hb}$ ). Without exception, all cardial deaths occurred in patients with severe valvular disease (with or without cardiac surgery). 
Table 3. Hemodynamic variables and cardiac medication

\begin{tabular}{lccc}
\hline & Study start & Study end & p value \\
\hline Predialytic systolic blood pressure, $\mathrm{mm} \mathrm{Hg}$ & $165 \pm 8$ & $130 \pm 10$ & $<0.001$ \\
Predialytic diastolic blood pressure, $\mathrm{mm} \mathrm{Hg}$ & $92 \pm 8$ & $80 \pm 5$ & $<0.001$ \\
Predialytic heart rate, beats/min & 96.8 & 62.8 & $<0.001$ \\
Dose of B-blocker metoprolol (target dose $190 \mathrm{mg}$ ), $\%$ & 38.0 & 75.0 & $<0.001$ \\
Dose of ACE inhibitor ramipril (target dose $10 \mathrm{mg}), \%$ & 34.0 & 76.8 & $<0.001$ \\
Dose of ARB candesartan (target dose 32 mg), \% & 7.8 & 78.2 & $<0.001$ \\
\hline
\end{tabular}

The non-cardiac reasons for deaths were liver insufficiency, severe peripheral arterial ischemia with amputation and following septicemia, subdural hematoma malignancies, and severe gastrointestinal bleedings.

\section{Anemia Correction, Iron Parameters and LVMI}

Mean $\mathrm{Hb}$ was $11.2 \pm 2.2$ at baseline and rose to 14.1 $\pm 1.4 \mathrm{~g} / \mathrm{dl}(\mathrm{p}<0.001)$ at follow-up (table 5$)$. The mean dose of epoetin- $\beta$ was $153 \pm 27 \mathrm{IU} / \mathrm{kg} /$ week during the correction and $68 \pm 23 \mathrm{IU} / \mathrm{kg} /$ week during the maintenance phase (mean weekly dose 5,128 $\pm 1,348 \mathrm{IU} /$ week). Intravenous substitution with elemental iron resulted in a significant increase in serum iron and transferrin saturation ( $p<0.05$ and $p<0.01$, respectively). Transferrin saturation in the case of significantly decreased transferrin values - which is the rule in long-term HD patients - should not be taken into consideration for iron metabolism.

LVMI shows an inverse correlation with the $\mathrm{Hb}$ values - higher $\mathrm{Hb}$ values correlate with lower LVMI values. However, the additional cardiac triple therapy further lowers the LVMI values in the direction of the normal LVMI values (fig. 1). For further evaluation of the impact of anemia correction on the LVMI, we compared patients with similar $\mathrm{Hb}$ values $<10 \mathrm{~g} / \mathrm{dl}$ at baseline (matched pairs) in which complete anemia correction by epoetin- $\beta$ was achieved during the observation period. Regression of LVMI was highly significant after partial correction of anemia ( $\mathrm{Hb} 11.5-12.5 \mathrm{~g} / \mathrm{dl})$ with an additional highly significant effect $(\mathrm{p}<0.001)$ seen after complete correction to $\mathrm{Hb}$ values $>14 \mathrm{~g} / \mathrm{dl}$ (fig. 2).

\section{Impact of Anemia Correction and Cardiac Triple Therapy}

We conducted several multivariate analyses with LVMI as outcome variable to evaluate the effects of baseline LVMI, anemia correction and triple therapy on LVMI at follow-up. Baseline LVMI $(\mathrm{p}<0.001)$, Hb increase $(\mathrm{p}<0.03)$ and triple cardiac therapy $(\mathrm{p}<0.03)$ were significant and independent prognostic factors for a re-
Table 4. BMI and NYHA stages of HD patients $(\mathrm{n}=230)$

\begin{tabular}{llll}
\hline & Study start & Study end & p value \\
\hline BMI & $22.5 \pm 4.0$ & $23.6 \pm 4.3$ & $<0.05$ \\
NYHA class, $\%$ & & & \\
$\quad$ Class I & $<1$ & 40 & \\
Class II & 34 & 50 & \\
Class III & 47 & 9 & \\
Class IV & 18 & $<1$ & \\
\hline
\end{tabular}

Table 5. Anemia correction and iron parameter of HD patients $(\mathrm{n}=230)$

\begin{tabular}{lccl}
\hline & Study start & Study end & p value \\
\hline Hemoglobin, g/dl & $11.2 \pm 2.2$ & $14.1 \pm 1.4$ & $<0.001$ \\
Serum iron, $\mu \mathrm{g} / \mathrm{dl}$ & $52.6 \pm 38.5$ & $75.2 \pm 41.4$ & $<0.05$ \\
Transferrin, mg/dl & $167.6 \pm 38.6$ & $148.5 \pm 26.7$ & $<0.05$ \\
Transferrin saturation, \% & $27.2 \pm 15.6$ & $46.8 \pm 33.5$ & $<0.01$ \\
\hline
\end{tabular}

Normal values: Hb 14-18 g/dl, serum iron 59-158 $\mu \mathrm{g} / \mathrm{dl}$, transferrin $200-350 \mathrm{mg} / \mathrm{dl}$, transferrin saturation $16-45 \%$.

Table 6. Acid-base status und potassium level

\begin{tabular}{lccc}
\hline & Dialysis start & Dialysis end & p value \\
\hline $\mathrm{pH}$ & $7.38 \pm 0.05$ & $7.46 \pm 0.05$ & n.s. \\
$\mathrm{P}_{\mathrm{aCO}_{2}, \mathrm{~mm} \mathrm{Hg}}$ & $39.35 \pm 3.79$ & $40.17 \pm 3.36$ & n.s. \\
$\mathrm{P}_{\mathrm{aO}_{2}}, \mathrm{~mm} \mathrm{Hg}$ & $95.27 \pm 11.49$ & $97.19 \pm 16.34$ & n.s. \\
$\mathrm{HCO}_{3}, \mathrm{mmol} / 1$ & $22.45 \pm 2.32$ & $27.33 \pm 1.96$ & $<0.01$ \\
$\mathrm{BE}, \mathrm{mmol} / \mathrm{l}$ & $-3.10 \pm 1.34$ & $3.60 \pm 1.75$ & $<0.01$ \\
$\mathrm{~K}^{+}, \mathrm{mmol} / \mathrm{l}$ & $5.03 \pm 0.57$ & $3.68 \pm 0.61$ & $<0.01$ \\
\hline
\end{tabular}

n.s. $=$ Not significant.

duction in LVMI. Each increase in $\mathrm{Hb}$ by $1 \mathrm{~g} / \mathrm{dl}$ resulted in a further significant reduction in LVMI $(p<0.03)$. Surprisingly, $\beta$-blockers have shown the highest effect on LVMI regression $(\mathrm{p}<0.01)$. 


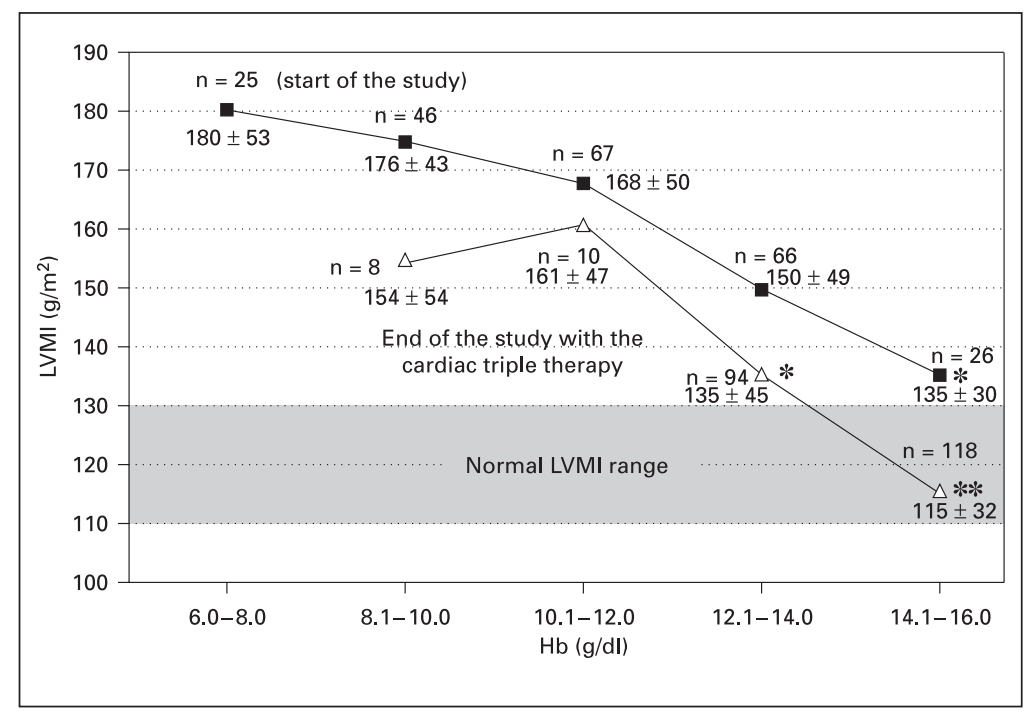

Fig. 1. Comparison of LVMI in HD patients $(\mathrm{n}=230)$ with similar $\mathrm{Hb}$ ranges at baseline and study end. At study end, after combination of cardiac triple therapy with anemia correction, a subgroup of 161 HD patients (70\% of the study group) showed a total LVMI regression (169 \pm 33 to $\left.114 \pm 14 \mathrm{~g} / \mathrm{m}^{2}\right)$. Significance $_{(\text {start/end) }}, \mathrm{p}<0.01{ }^{* *} \mathrm{p}<0.001$.

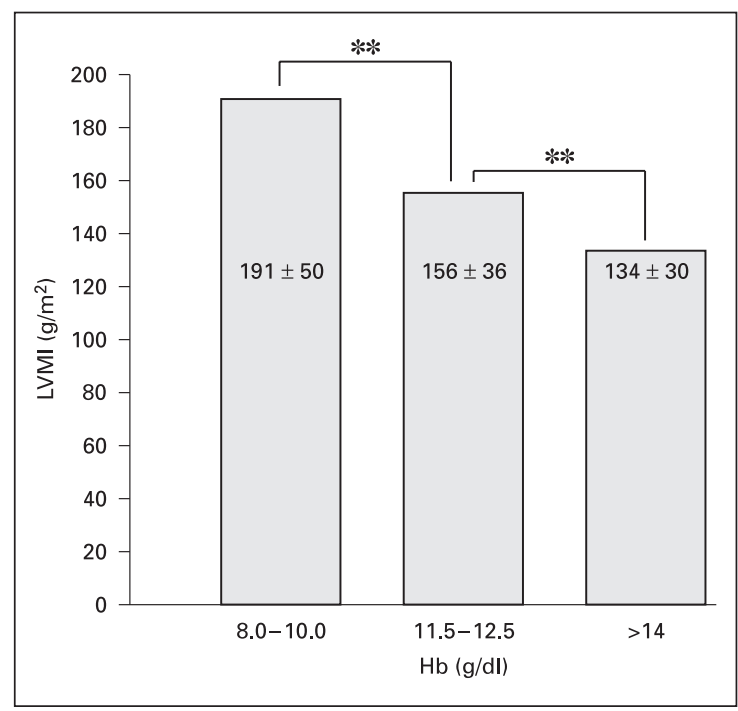

Fig. 2. Effect of total versus partial anemia correction on LVH over time in a subgroup of 60 patients with similar blood $\mathrm{Hb}$ levels $(<10 \mathrm{~g} / \mathrm{dl})$ (matched pairs) at baseline and complete anemia correction $(\mathrm{Hb}>14 \mathrm{~g} / \mathrm{dl})$ at follow-up. Regression of LVMI with a highly significant reduction after partial correction $(\mathrm{Hb} 11.5$ $12.5 \mathrm{~g} / \mathrm{dl}$ ) and additional highly significant effects seen after complete correction $(\mathrm{Hb}>14 \mathrm{~g} / \mathrm{dl})$. $* * \mathrm{p}<0.001$.

\section{Correction of Metabolic Acidosis}

Acid-base status and potassium levels before and after HD are given in table 6 . The correction of metabolic acidosis was optimized resulting in stabilized potassium values.

\section{Discussion}

The main finding of the present study is that a multiinterventional approach, which contained optimized therapy with $\beta$-blockers, ACE inhibitors and ARBs with complete anemia correction, results in a significant reduction in LVMI.

In contrast to the expected natural progression of $\mathrm{LVH}$ in HD patients over time, we were able to demonstrate that regression and prevention of LVH is possible. Even in the high-risk subgroup of HD patients, namely those with CAD, diabetes mellitus, hypertension or those with very low LVEF, regression of LVH was achieved [18]. Since the presence and/or progression of $\mathrm{LVH}$ has emerged as an independent prognostic factor, LVH has become accepted as a surrogate parameter for mortality/ morbidity outcomes in end-stage renal disease patients [1-5].
Our data suggest an improvement in prognosis of HD patients by our multi-interventional treatment strategy. However, LVH develops over a long period of time; therefore, regression may take equally long (on average 23.2 months for concentric and 24.1 months for excentric LVH). Most importantly, the results of this study also demonstrate that our treatment strategy resulted in significant improvement in NYHA class and LVEF, which was also consistent across high-risk subgroups [18].

Oxygen delivery by complete correction of anemia is a corner stone of therapy. The diseased heart requires extra energy due to increased work load. Therefore, a higher than normal oxygen availability is absolutely necessary.

In contrast to the skeleton muscle, the energy metabolism of the heart muscle is constantly aerobic (aerobic glycolysis yields nearly 20-fold energy - approximately $2,840 \mathrm{~kJ} / \mathrm{mol}$ glucose - in comparison with anaerobic glycolysis - $146 \mathrm{~kJ} / \mathrm{mol}$ glucose). [19]. Thus, LVMI shows an inverse correlation with the $\mathrm{Hb}$ values - higher $\mathrm{Hb}$ values correlate with lower LVMI values (fig. 1,2) in the HD patients before cardiac triple therapy, as well as in the patients with the cardiac triple therapy. However, the additional neurohumoral blockage via the cardiac triple therapy is necessary to decrease the LVMI values to normal range in $70 \%$ of the patients (fig. 1). 
HD patients are known to have either a high prevalence or a high risk for developing CHF [20, 21]. Left ventricular diastolic and systolic dysfunction and $\mathrm{CHF}$ have a particularly poor prognosis, are prevalent in uremic patients $[22,23]$, and therefore, may account for much of the high morbidity and mortality $[23,24]$. Consequently, appropriate therapy should be implemented as early as possible in HD patients.

However, the baseline data of our study show a large underprescription of cardiac therapy, insufficient anemia control and poor control of hypertension. Despite the well-documented prevalence of CAD and hypertension, especially ACE inhibitors, $\beta$-blockers and ARBs were largely underprescribed, demonstrating that the majority of patients are not receiving optimized cardioprotective therapy.

From a pathophysiological perspective, a combined and comprehensive blockade of RAAS, with a combination of an ACE inhibitor and ARB, together with inhibition of the sympathetic system by a $\beta$-blocker, makes sense, since both systems are activated in HD patients $[25,26]$. The results of multivariate analysis suggested maximal effects in terms of LVMI regression by using cardiac triple therapy.

Cardiac mortality in uremic patients depends on multifactorial causes. To correct only one cause would not be sufficient. A multifactorial therapeutic approach is necessary to achieve improvement in cardiac morbidity/mortality. The recent study of Parfrey et al. [28] suffers from a lack of an optimized multi-interventional therapeutic strategy.

In this study [28], 46\% of the baseline group is lost, but involved in the baseline characteristics. The authors reported an improved SF-36 vitality score in a higher versus a lower $\mathrm{Hb}$ group. The data of this double-blind study showed a relative decrease in mortality/cardiac risk (approximately $62 \%$ ) of the higher $\mathrm{Hb}$ group. Together with the improved SF-36 vitality score, this is an interesting result. Nevertheless, they did not find a beneficial effect on their reported cardiac measurements. No data of the acid-base values were mentioned. During therapy with erythropoietin, acid-base control is mandatory because the optimal oxygen exhaustion from the red blood cells depends on optimal corrected metabolic acidosis. The difference in $\mathrm{Hb}$ between the two study arms was too small and not significant in difference over time. $\mathrm{The} \mathrm{Hb}$ values were $10.9 \pm 0.7$ and $13.1 \pm 0.9 \mathrm{~g} / \mathrm{dl}$, respectively. These values are different from the announced target values described in the abstract. Normal values of $\mathrm{Hb}(>14 \mathrm{~g} /$ dl) are not reached in the study.

Reduced Uremic Cardiovascular Mortality
In previous studies, Foley et al. [22, 29] and Harnett et al. [23] have pointed out that the prevalence of clinical manifestation of cardiac disease at the start of dialysis is very high. In the recent study which they performed with 596 patients who started dialysis, all of them were without clinical manifestations of cardiac disease. It is not clear whether they have done a highest selection of their patients. However, it is well know that only a small number of patients $(15 \%)$ have a cardiac stage without any cardiac disease at the first months of dialysis.

It is very important to define the initial cardiac stage of the patients. Fifty percent of heart failure patients have severe diastolic dysfunction in the presence of normal LVEF. Up to now, there is no reliable technical method to measure diastolic dysfunction. Therefore, it is mandatory to clinically define heart failure by NYHA stages. However, NYHA stages are not mentioned in the study of Parfrey et al. [28]. The definition of heart failure was given as 'dyspnea at rest' which corresponds to NYHA stage IV, the worst stage of NYHA classification.

Eighteen percent of patients suffered from diabetes mellitus. According to new guidelines, diabetes per se can be considered as stage I heart failure at the onset of the illness. Patients suffering from both diabetes mellitus and renal insufficiency have disproportionally high rates of $\mathrm{LVH}$, which means high rates of cardiac failure. In $8 \%$ of patients, the primary cause of renal insufficiency was arterial hypertension. It does not seem possible that such patients could be excluded from heart failure.

Cardiologically, patients are very poorly defined. Therefore, the term 'without cardiac failure' is obviously restricted. Last but not least, cardiac comedication was not mentioned. We are convinced that in this study, similar results to our study would have been found if a similar multifactorial approach of complete anemia correction including triple therapy with $\beta$-blockers, ACE inhibitors and ARBs had been introduced. Strict control of hypertension is necessary to achieve maximal beneficial effects regarding cardiac morbidity/mortality in patients. The responsibility for our uremic patients is very high.

\section{Study Limitations}

The number of 230 long-term dialysis patients, on average 13 years on dialysis (longest 30-37 years), does not allow for prospective statistics in our multifactorial study design. Therefore, we used the retrospective multivariate analysis. The data of our clinical study should be taken into consideration in the ongoing discussion. 


\section{Conclusion}

Our data show that optimized cardiac therapy in combination with complete anemia correction is not only successful, but also a safe therapy and leads to a significant improvement in cardiac function and reduced mortality. Besarab et al. [27] reported that partial correction of anemia is safer than complete normalization of $\mathrm{Hb}$ values due to adverse cardiac events. In contrast, we found that best results are achieved using a multi-interventional approach. Optimized oxygen availability and correction of hormonal abnormality are needed for the diseased heart to heal. Complete correction of anemia was essential, safe and economical in our patient population.

Nephrologists need to be responsible for the cardiac health of chronic kidney disease patients. Renal physicians can do a lot of good, and bad, for the cardiac health of their patients.

\section{References}

$\checkmark$ Silberberg JS, Barre PE, Prichard PS, Sniderman AD: Impact of left ventricular hypertrophy on survival in end-stage renal disease. Kidney Int 1989;36:286-290.

2 Foley NF, Parfrey PS, Harnett JD, Kent GM, Murray DC, Barre BE: The prognostic importance of left ventricular geometry in uremic cardiomyopathy. J Am Soc Nephrol 1995;5: 2004-2031.

-3 Foley RN, Parfrey PS, Harnett JD, Kent GM, Murray DC, Barre PE: The impact of anemia on cardiomyopathy, morbidity, and mortality in end-stage renal disease. Am J Kidney Dis 1996;28:53-61.

-4 Foley RN, Parfrey PS, Kent GM, Harnett JD, Murray DC, Barre PE: Serial echocardiographic parameters and cardiac failure in end-stage renal disease. J Am Soc Nephrol 2000;11:912 916.

5 Zoccali C, Benedetto FA, Mallamaci F, Tripepi G, Giacone G, Stancanelli B, Cataliotti A, Malatino LF: Left ventricular mass monitoring in the follow-up of dialysis patients. Prognostic value of left ventricular hypertrophy progression. Kidney Int 2004;65:1492-1498.

-6 Levy D, Garrison RJ, Savage DD, Kannel WB Castelli WP: Prognostic implications of echocardiagraphically determined left ventricular mass in the Framingham Heart Study. N Engl J Med 1990;322:1561-1566.

-7 Koren MJ, Devereux RB, Casale PN, Savage DD, Laragh JH: Relation of left ventricular mass and geometry to morbidity and mortality in uncomplicated essential hypertension. Ann Intern Med 2001;114:345-352.

8 Benjamin EJ, Levy D: Why is left ventricular hypertrophy so predictive of morbidity and mortality? Am J Med Sci 1999;317:168-175.

9 Devereux R, Reichek N: Echocardiographic determination of left ventricular mass in man. Anatomic validation of the method. Circulation 1977; 55:1325-1350.

10 Devereux RB, Lutas EM, Casale PN, Kligfield $\mathrm{P}$, Eisenberg RR, Hammond IW, Miller DH, Reis G, Aldermann AH, Laragh JH: Standardization of M-mode echocardiographic left ventricular anatomic measurements. J Am Coll Cardiol 1984;4:1222-1230.
11 Berger AK, Duval S, Krumholz HM: Aspirin, beta-blocker, and angiotensin-converting enzyme therapy in patients with end-stage renal disease and acute myocardial infarction. $\mathrm{J}$ Am Coll Cardiol 2003;42:209-210.

12 Tonelli M, Bohm C, Pandeya S, Gill J, Levin A, Kiberd BA: Cardiac risk factors and the use of cardioprotective medications in patients with chronic renal insufficiency. Am J Kidney Dis 2001;37:484-489.

13 Griffith TF, Chua BSY, Allen AS, Klassen PS, Reddan DN, Szczech LA: Characteristics of treated hypertension in incident hemodialysis and peritoneal dialysis patients. Am J Kidney Dis 2003;42:1260-1269.

14 Herzog CA, Ma JZ, Collins AJ: Poor long-term survival after acute myocardial infarction among patients on long-term dialysis. $\mathrm{N}$ Engl J Med 1998;339:799-805.

15 Trespalacios FC, Taylor AJ, Agodoa LY, Bakris GL, Abbott KC: Heart failure as a cause for hospitalization in chronic dialysis patients. Am J Kidney Dis 2003;41:1267-1277.

16 Amann K, Buzello M, Simonavicienc A, Miltenberger-Miltenyi G, Koch A, Nabokov A, Gross ML, Gless B, Mall G, Ritz E: Capillary/ myocyte mismatch in the heart in renal failure - A role for erythropoietin? Nephrol Dial Transplant 2000;15:964-969.

17 Hampl H: Hemodynamic state in severe chronic renal failure. Nephron 1985;39:102_ 111.

18 Hampl H, Hennig L, Rosenberger $\mathrm{CH}$, Amirkhalily M, Gogoll L, Riedel E, Scherhag A: Effects of optimized heart failure therapy and anemia correction with epoetin beta on left ventricular mass in hemodialysis patients. Am J Nephrol 2005;25:211-220.

19 Lehninger AL, Nelson DL, Cox MM: Prinzipien der Biochemie. Heidelberg, Spektrum, 1994, p 851.

20 Foley RN, Parfrey PS, Morgan J, Barre PE, Campbell P, Cartier P, Coyle D, Fine A, Handa P, Kingma I, Lau CY, Levin A, Mendelssohn D, Muirhead N, Murphy B, Plante RK, Posen G, Wells GA: Effects of hemoglobin levels in hemodialysis patients with asymptomatic cardiomyopathy. Kidney Int 2000;58: $1325-1335$
21 US Renal Data System, USRDS 2002 annual data report: atlas end-stage renal disease in the United States. Bethesda, NIH, National Institute of Diabetes and Digestive and Kidney Disease, 2002.

22 Foley RN, Parfrey PS, Sarnak MJ: Clinical epidemiology of cardiovascular disease in chronic renal disease. Am J Kidney Dis 1998;32 (suppl 3):112-119.

23 Harnett JD, Foley RN, Kent GM, Barre PE Murray D, Parfrey PS: Congestive heart failure in dialysis patients: prevalence, incidence, prognosis and risk factors. Kidney Int 1995;47: 884-890.

24 Schreiber BD: Congestive heart failure in patients with chronic kidney disease and on dialysis. Am J Med Sci 2003;325:179-193.

-25 Vlahakos DV, Hahalis G, Vassilakos P, Marathias KP, Geroulanos S: Relationship between left ventricular hypertrophy and plasma renin activity in chronic hemodialysis patients. J Am Soc Nephrol 1997;8:1764-1770.

-26 Hausberg M, Kosch M, Harmelink P, Barenbrock M, Hohage H, Kisters K, Dietl KH, Rahn KH: Sympethetic nerve activity in endstage renal disease. Circulation 2002;106: 1974-1979.

- 27 Besarab A, Bolton WK, Browne JK, Egrie JC, Nissenson AR, Okamoto DM, Schwab SJ, Goodkin DA: The effects of normal versus low treated hematocrit values in hemodialysis patients with cardiac disease with erythropoietin. N Engl J Med 1998;339:584-590.

- 28 Parfrey PS, Foley RN, Wittreich BH, Sullivan JD, Zagari MJ, Frei D: Double-blind comparison of full and partial anemia correction in incident hemodialysis patients without symptomatic heart disease. J Am Soc Nephrol 2005;16:2180-2189.

29 Foley RN, Parfrey PS, Harnett JD, Kent GM, Martin CJ, Murray DC, Barre BE: Clinical and echocardiographic disease in patients starting end-stage renal disease therapy. Kidney Int 1995;47:186-192. 